\title{
CONTRIBUIÇÕES DE AUTORES CLÁSSICOS MODERNOS E CONTEMPORÂNEOS PARA OS ESTUDOS DO LAZER
}

\author{
Recebido em: 18/05/2010 \\ Aceito em: 02/11/2010 \\ Nelson Carvalho Marcellino ${ }^{1}$ \\ Mestrado em Educação Física - Unimep \\ Piracicaba - SP - Brasil
}

RESUMO: O presente artigo de revisão bibliográfica faz uma análise cronológica dos autores que se dedicaram aos estudos do lazer e que contribuíram para a construção do que se pode chamar de Teoria do Lazer. Eles têm as mais variadas formações, o que confirma que o lazer é um campo multidisciplinar de estudos, em busca da interdisciplinaridade. Suas contribuições devem ser levadas em conta segundo o tempo/espaço em que viveram e conforme suas filiações ideológicas. Suas abordagens ora são diretas, ora indiretas, e a consideração do lazer ocorre tanto numa perspectiva idealista quanto concreta. No conjunto, os autores demonstram que o lazer tem sua especificidade, mas que deve ser entendido no plano cultural do qual faz parte e em suas relações com o terreno das obrigações, destacando-se as relações lazer e trabalho.

PALAVRAS-CHAVE: Atividades de Lazer. Sociologia. Filosofia.

\section{CONTRIBUTIONS OF MODERN AND CONTEMPORARY CLASSICAL AUTHORS TO THE STUDY OF LEISURE}

ABSTRACT: The present literature review paper brings a chronological analysis of authors who have devoted themselves to the study of leisure and have contributed to the so-called Theory of Leisure. They come from several different educational backgrounds, which confirms that leisure is a multidisciplinary field of studies and is seeking interdisciplinarity. Their contributions must be considered according to the time and place they lived in, and also their ideological affiliation. Their approaches are sometimes direct and sometimes indirect, and leisure is understood both in an idealistic and a concrete perspective. As a whole, the authors show that leisure has its own specificity, but it must be understood in the cultural context it is part of and in its relations with the field of obligations, emphasizing the relations between leisure and work.

KEYWORDS: Leisure Activities. Sociology. Philosophy.

1 Docente do mestrado e graduação em Educação Física da Unimep; coordenador do Núcleo da Rede Cedes, líder do Grupo de Pesquisa em Lazer (GPL), Unimep; membro do ORICOLÉ, Laboratório de pesquisa sobre formação e atuação profissional, UFMG, e pesquisador do CNPq. 


\section{Introdução}

Os termos "teoria" e "prática" são bastante utilizados no senso comum, o que levou a um desgaste quanto ao seu entendimento, inclusive nos meios acadêmicos, principalmente naquelas áreas ligadas à prática de atividades.

Em geral, entende-se "teoria" como uma especulação ou como "discurso vazio", desvinculado da realidade vivida no concreto, e "prática", como uso, experiência desvinculada da "teoria", o que a transforma, como regra, em tarefa ou ação desprovida de sentido.

Se entendermos "teoria" como um conjunto de conhecimentos não ingênuos, com graus diversos de sistematização e credibilidade e que se propõem explicar, elucidar, interpretar e unificar um dado domínio de problemas que se oferecem à atividade prática, e "prática" como saber provindo da experiência e, ao mesmo tempo, aplicação da teoria, poderíamos, ao invés de sua dicotomia, compreender o que Saviani (1980) denomina "dialética estabelecida entre ação, reflexão, ação". Dessa forma chegaríamos não a uma dicotomia teoria e prática, mas a um conceito que não lhes esgotasse a extensão, ou seja, a uma unidade que não pode e não deve ser entendida como unificação, no que se chama de "práxis": entender-se-ia que não existe atividade sem projeto, ato sem programa (FORACCHI; MARTINS, 1981).

Assim, não é necessária a criação de uma ciência específica para a elaboração de uma teoria sobre uma determinada problemática, mas esta pode ser estabelecida a partir da contribuição de várias ciências e da reflexão filosófica, ou seja, da filosofia entendida enquanto produto e, sobretudo, enquanto processo.

É importante destacar, ainda, que a teoria, exatamente por guardar estreita relação com o agir humano, não é neutra, possuindo não apenas uma dimensão lógica, mas também uma dimensão antropológica (PEREIRA, 1982). Não são puramente 
objetivas, mas carregam alto grau de historicidade e subjetividade. Assim, sobre um mesmo assunto, uma mesma problemática, existem, e devem existir, teorias divergentes e até antagônicas, dependendo das concepções que as embasam.

Podemos considerar que existe uma teoria do lazer, desconhecida da grande maioria dos profissionais que atuam na área. Esta teoria vem sendo formulada desde a filosofia clássica, ganhou impulso com a criação e desenvolvimento das Ciências Humanas, entre a segunda metade do século XVIII e a primeira metade do século XIX, e tem recebido contribuições constantes da Sociologia, Antropologia, Arquitetura/Urbanismo, Comunicações etc.

Desconhecendo a teoria do lazer, o profissional que atua nessa área, além de confundir a prática do lazer com a prática profissional que o lazer requer, não estabelece uma prática, mas sim um "tarefismo". Isso pode ser verificado nas aulas de graduação de muitos cursos superiores e nos "manuais" de recreação e lazer.

A teoria do lazer, sobretudo embasada em autores clássicos, é imprescindível para fundamentar projetos específicos de investigação que relacionem atividades físicas e/ou modalidades esportivas associadas ao componente lúdico da cultura, ou para as relações entre o lazer e as demais esferas da vida social (MARCELLINO, 1995).

\section{Metodologia}

O trabalho foi efetuado por meio de pesquisa bibliográfica (PARRA FILHO; SANTOS, 2002, RAMPAZZO, 2002, HUHNE, 2002, SANTOS, 1999, ECO, 1977).

O material bibliográfico para a pesquisa vem sendo selecionado há mais de 20 (vinte) anos durante o desenvolvimento da disciplina Teoria do Lazer, primeiro nos cursos de mestrado e doutorado em Educação Física, da Unicamp, e agora no curso de mestrado em Educação Física da Unimep. 
Esse trabalho foi complementado e atualizado a partir de levantamento bibliográfico efetuado no Sistema de Bibliotecas da Unimep e Unicamp e em ferramentas disponíveis na Internet.

As obras selecionadas foram lidas e examinadas por meio de análise textual, temática, interpretativa e crítica (SEVERINO, 1980).

Cada conjunto de obras foi apresentado e discutido, por ordem cronológica, em seminários internos do Grupo de Pesquisa em Lazer (GPL), registrado no $\mathrm{CNPq}^{2}$, recebendo contribuições dos integrantes do grupo através de resenhas e dos roteiros dos seminários.

\section{Desenvolvimento}

Como todas as questões que envolvem a vida social, a do lazer também tem antecedentes bastante longínquos, em termos de reflexão. O ócio, o não-trabalho, foi motivo de preocupação para uma série de nomes da Filosofia Social no mundo ocidental. Mas é, sobretudo, a partir do advento da chamada "sociedade industrial", que o lazer foi ganhando importância na produção dos pensadores sociais do século XIX.

Motivado pelas condições do trabalho industrial na Europa, que desrespeitavam um mínimo de dignidade para o ser humano, surgiu o primeiro "manifesto" em favor do lazer dos operários, o clássico $O$ direito à preguiça, do militante socialista Paulo Lafargue (1842-1911). Publicado em 1883, o "panfleto" baseia-se nas idéias de Marx e seu ideário tem em Gramsci um de seus representantes, por sua contribuição para a recuperação do valor da atuação no plano cultural, visando preparar mudanças estruturais na sociedade.

2 Ver: www.unimep. br/gpl. 
Lafargue caracteriza seu $O$ direito à preguiça como "refutação do direito ao trabalho", contrapondo-se à moral cristã do trabalho e fazendo o elogio da preguiça. Parte do pressuposto de que o trabalho é um dogma desastroso e analisa criticamente suas bênçãos, argumentando que "o trabalho só se tornará um condimento de prazer da preguiça, um exercício benéfico para o organismo humano, uma paixão útil ao organismo social, quando for prudentemente regulamentado e limitado a um máximo de três horas por dia" (1970, p. 31).

À luz desse pressuposto, analisa o que se segue à superprodução, a partir de uma crença ingênua na máquina e suas possibilidades para o ser humano. Denuncia o trabalho de crianças e mulheres e vê a libertação do ser humano como um todo, independentemente de classes sociais.

Na última parte de $O$ direito à preguiça, Lafargue descreve sua utopia, numa sociedade regulada por um "regime de preguiça".

Em prefácio à edição de 1999, Marilena Chauí analisa os desdobramentos da sociedade pós-Lafargue e destaca que, longe de ter sido superada pelo desenvolvimento histórico, a obra de Lafargue é atual numa sociedade que independe da "exploração mortal do trabalho", e coloca que, numa situação de desemprego, $O$ direito à preguiça pode significar o resgate da "dignidade e o auto-respeito dos trabalhadores", que passarão a lutar "não mais pelo direito ao trabalho, e sim pela distribuição social da riqueza e pelo direito de fruir de todos os seus bens e prazeres" (LAFARGUE, 1999, p. 56).

Chauí analisa o contexto histórico em que a obra foi escrita, colocando que o autor tem como pressuposto fundamental o "significado do trabalho no modo de produção capitalista, isto é, a divisão social do trabalho e a luta de classes” (Ibid., p. 33) e aduz que Lafargue tem como inspiração “de um lado as ideias do jovem Marx [1818- 
1883], nos Manuscritos econômicos de 1844, sobre o trabalho alienado, e, de outro, a análise do trabalho assalariado, no primeiro volume de $O$ capital" (Ibid., p. 33).

É importante observar como essas duas obras de Marx (1989 e 1988) contribuem para a análise do lazer quando se faz a relação entre "trabalho" e "não trabalho". Isso pode ser observado em autores marxistas que geralmente comparam o trabalho ideal com o lazer concreto, e autores dos estudos do lazer que comparam o lazer ideal com o trabalho concreto.

$\mathrm{Na}$ análise da necessidade de uma revolução cultural que colabore com uma reforma intelectual e moral, tendo em vista a constituição de uma nova ordem social, destaca-se Antonio Gramsci (1891-1937). Os escritos de Gramsci (1978, 1979, 1980, 1981) são marcados por uma estreita vinculação entre sua prática (ação) e seu pensamento (teoria), depurados pelo isolamento no cárcere. Essa característica geral é observada sobretudo no domínio das atividades culturais. No materialismo histórico, Gramsci situa-se como o grande responsável pelo resgate do valor do plano cultural, ou seja, pela percepção de que o componente de persuasão - no sentido de impor os valores culturais e morais da classe dominante - desempenha papel importante em sua "hegemonia". Suas reflexões, calcadas nas experiências vividas, na observação e na análise de diversos autores são, em regra, consolidadas em diretrizes para o estabelecimento de uma política cultural.

Os objetivos dessa política situam-se em duas frentes interligadas: uma de derrubada da ideologia dominante, e outra de reconstrução. Em síntese, o que se busca em ambas as frentes é a renovação democrática e humanista da cultura e da sociedade, tendo em vista uma sociedade que obedeça não só uma economia planificada e socializada, mas uma nova cultura, uma comunidade humana real e autêntica. Para tanto 
é necessária uma reforma intelectual e moral ou, em outras palavras, uma revolução cultural.

Mas foi preciso esperar até as primeiras décadas do século XX, para que se desenvolvesse o estudo sistemático da questão do lazer, tanto nos Estados Unidos quanto na Europa. No pós-guerra, as investigações sobre o lazer ganharam uma nova dimensão, em virtude do próprio contexto histórico. Anteriormente, no entanto, a questão já havia sido analisada por filósofos como Bertrand Russel, que em 1932 publicava o seu Elogio do lazer, Huizinga, com o Homo ludens, de 1938, ou Veblen, do clássico Teoria da classe ociosa, que data do início do século XX.

O pensador Bertrand Russel (1872-1970) tem uma obra bastante fecunda e, entre outras posições, mostrou-se confiante com relação à técnica e à ciência, contribuindo para o bem-estar coletivo. Em seu Elogio do lazer (1977), publicado pela primeira vez em 1932, defende sua postura ao examinar as relações entre trabalho e lazer, colocando seu desencanto com relação ao primeiro e analisando as possibilidades do segundo.

Referindo-se aos operários, o autor coloca que eles "consideram o trabalho como deve ser considerado. Isto é, um meio de ganhar a vida, e é de seu tempo de lazer que eles obtêm qualquer possibilidade que possam desfrutar" (RUSSEL, 1977, p. 20). Em seu raciocínio utópico, baseado na crença ingênua da redenção humana por meio da máquina e da tecnologia, e dentro de uma visão socialista, defende a redução do trabalho diário a quatro horas semanais (Ibid., p. 14 e 15), e considera que o "emprego sábio" do lazer "é fruto da civilização e da educação" (Ibid., p. 17).

No clássico Homo ludens (1971), lançado em 1938, o historiador Johan Huizinga (1872-1945) contribuiu significativamente para os estudos do lazer ao examinar o lúdico, a partir do desenvolvimento histórico e para além de suas 
características biológicas, como fenômeno cultural, analisando sua natureza e significado.

Huizinga tem uma visão idealista do jogo, apresentada logo no primeiro capítulo da obra. Sua análise histórica do elemento lúdico da cultura constata sua decadência, ou seja, ele vem perdendo força na sociedade, sobretudo no século XIX, comparativamente ao século XVIII, "época em que florescia plenamente" (HUIZINGA, 1971, p. 229). É a partir dessa perspectiva que se podem ver suas críticas ao esporte e à arte na cultura da época.

Em sua análise do componente lúdico da cultura, o autor coloca o jogo como base da cultura, vista antropologicamente, e conclui que "a verdadeira civilização não pode existir sem um certo elemento lúdico" (Ibid., p. 234).

Caillois faz uma crítica a Huizinga em $O$ homem e o sagrado (1988), publicado originalmente em 1950. Analisa as relações entre jogo e sagrado, discordando das ideias apresentadas a este respeito em Homo ludens, considerando essas relações as "mais audaciosas da obra" e, ao mesmo tempo as "mais frágeis de todas" (p. 152). Para Caillois, "Homo ludens termina por um capítulo amargo sobre a decadência do elemento lúdico nos tempos contemporâneos. Talvez haja apenas aqui a ilusão de óptica laudator temporis acti. É conveniente desconfiar" (CAILLOIS, 1988, p. 160).

Humberto Eco, em Sobre os espelhos e outros ensaios (1989), no capítulo "Huizinga e o jogo", reconhece as significativas e originais contribuições do autor, mas dirige a ele várias críticas. Também destaca o encerramento de Homo ludens "com um fantasma que nega toda a sua teoria" e sublinha que "a consciência moral e o "Sumo Bem' aparecem na cena do jogo para advertir que o jogo acabou” (ECO, 1989, p. 284).

O economista Thorstein Veblen (1857-1929) traz contribuições a uma possível teoria do lazer, em seu livro A teoria da classe ociosa (1965), originalmente publicado 
em 1904, sob o título The theory of the leisure class. Partindo de uma abordagem histórica, nem sempre bem fundamentada, constata que a instituição da classe ociosa "surgiu gradualmente durante a transição da selvageria primitiva para o barbarismo, ou, mais precisamente, durante a transição de um modo de vida pacífico para um mais consistentemente guerreiro" (VEBLEN, 1965, p. 24).

O autor parte do conceito de "emulação", distinguindo-a, historicamente, com base na proeza (cuja sobrevivência moderna se dá, entre outros setores, pelo esporte), e posteriormente, pelo acúmulo de dinheiro (emulação pecuniária), pelo ócio conspícuo (distintivo) e pelo consumo conspícuo.

Como a emulação nasce com a proeza, ele situa a dominação de sexos como anterior à dominação de classes, sugerindo, já em 1904, que a revolução feminina seria mais importante que a revolução proletária.

No caso do ócio, sua conotação no estudo não implica indolência, mas simplesmente "tempo gasto de modo não produtivo" (p. 54). Distingue também o ócio vicário (feito em nome de outrem) (Ibid., p. 67 a 73).

Adorno estabelece críticas a Veblen nas relações entre a teoria da classe ociosa com a cultura (1998).

A partir dos anos de 1950, o lazer passa a ser objeto de estudo sistemático nas modernas sociedades urbano-industriais. Entre os vários trabalhos publicados destacaram-se, por sua repercussão, os de David Riesman, A multidão solitária, Friedmann, O trabalho em migalhas, e Mills, A nova classe média: white collar, além das contribuições de Caillois para o estudo do jogo.

O sociólogo David Riesman (1909-2002), em um estudo sobre a mudança do caráter americano, publicado originalmente em 1950, parte do conceito de "caráter social”, por ele definido como "a parte do 'caráter' que é compartilhada por grupos 
significativos, e que [...] é o produto da experiência destes grupos" (RIESMAN, 1975, p. 68).

No decorrer do estudo, baseado em curvas demográficas de natalidade e mortalidade, chega a definir três tipos ideais de sociedade: tradicional, de produção e de consumo, cada qual exigindo um tipo de caráter social (histórico). Assim, a sociedade tradicional exige pessoas traditivo-dirigidas, a sociedade de produção busca pessoas introdirigidas, e a sociedade de consumo, pessoas alterdirigidas. Além desses tipos históricos, distingue três tipos psicológicos de caráter social: o ajustado, o anômico e o autônomo. Sua importante contribuição para os estudos do lazer consiste em analisá-lo nos três tipos de sociedade e nos caracteres históricos e psicológicos.

Em um dos capítulos do livro, intitulado "A privatividade imposta: obstáculos à autonomia na diversão", o autor afirma que esta última, "longe de ser obrigatoriamente a esfera residual do período de trabalho e do sentimento de trabalho, poderá cada vez mais tornar-se a esfera para o desenvolvimento na arte de viver" (RIESMAN, 1975, p. 347). Examina alguns dos obstáculos à concretização dessa ideia, como a recusa da sociabilidade, a privatização da mulher, as sociabilidades empacotadas. Detecta a necessidade dos "consultores de lazer", e faz considerações sobre o "mercado infantil".

O autor constata que:

Se os indivíduos alterdirigidos viessem a descobrir quanto trabalho inútil eles fazem, a descobrir que seus próprios pensamentos e suas próprias vidas valem tanto quanto o pensamento e a vida dos outros, e que, na verdade, não lhes é dado mitigar sua solidão dentro de uma multidão de pares, mais do que se pode mitigar a sede bebendo água do mar, então poderíamos esperar que eles se tornassem atentos a seus próprios sentimentos e aspirações (RIESMAN, 1975, p. 378).

Em prefácio escrito em novembro de 1960, Riesman revê sua obra e destaca que “a única nota fortemente utópica que permanece no livro, parece-nos, agora, a menos satisfatória, isto é, a ideia toda de que a autonomia na cultura pós-industrial deveria 
encontrar-se no jogo e lazer, e não no trabalho" (p. 59), aceita a crítica de Daniel Bell em Work and its discontents, que o considera um dos "profetas da diversão", e concorda com a ideia de Paul Godman, em Growing up absurd, de que os homens precisam sentir-se adequados.

O sociólogo francês Georges Friedmann (1902-1977), embora tenha dedicado seus esforços a analisar as questões referentes ao trabalho, traz em seu livro $O$ trabalho em migalhas, publicado originalmente em 1964, significativa contribuição aos estudos do lazer. O livro, que tem como subtítulo "especialização e lazeres", analisa detidamente a alienação do trabalho, levando em conta a questão de sua fragmentação, concluindo que "a insatisfação do trabalho em migalhas constitui [...] um dos principais aspectos dessa alienação" (FRIEDMANN, 1972, p. 170).

Quanto ao lazer, o assunto é tratado especificamente no capítulo "Os lazeres e a insatisfação do trabalho", em que o autor distingue a existência de "um único e mesmo homem", que trabalha e tem lazer, e indaga se neste último seriam realizadas atividades "laterais" ou essenciais.

São muito importantes suas análises sobre as relações entre trabalho e tempo livre e sobre os "lazeres ativos": "o verdadeiro lazer ativo é também um lazer livremente escolhido, praticado no momento e da maneira esperada por aquele que dele aguarda a satisfação e até mesmo um certo desenvolvimento" (FRIEDMANN, 1972, p. 162).

Para Friedmann a insatisfação no trabalho pode exercer influências sobre a vida fora do trabalho, traduzindo-se pela "evasão", em atividades laterais. Destaca, entretanto, que "há diversas formas de evasão no lazer, das quais os dois pólos são, numa extremidade, a conduta chamada de 'matar o tempo' e, na outra, o autêntico lazer ativo" (Ibid., p. 169). 
Nessa linha de raciocínio, o autor destaca "a importância crescente que, tudo o demonstra, deve assumir agora o tempo 'fora do trabalho' para a humanização da civilização técnica" (Ibid., p. 183), mas vê com reservas o que chama de "nova utopia técnica" (Ibid., p. 176).

Ao contrário de outros autores que, ao examinarem o lazer "demonizam" o trabalho, Friedmann mostra a importância de ambos na vida do ser humano, apontando a "extraordinária importância" de seu papel, que, segundo o autor, pode ser verificada empiricamente pela observação do comportamento dos indivíduos que dele estão privados. Nesse sentido, examina alguns efeitos da privação do trabalho pelo desemprego e pela aposentadoria, e as relações entre trabalho e saúde mental (p. 192200).

O sociólogo Charles Wright Mills (1916-1962), em A nova classe média: white collar, publicado em 1951, traz importantes contribuições à relação trabalho e lazer, já em sua Introdução. Mas suas reflexões mais significativas sobre o assunto estão no item III do livro, "Estilos de vida", onde analisa o "trabalho", seu "modelo artesanal" (em que uma das características é "nenhuma separação entre trabalho e divertimento, entre trabalho e cultura" [MILLS, 1969, p. 240]), "as atuais condições de trabalho", "atitudes para com o trabalho" e "a moral dos alegres robôs", não vendo no trabalho atual qualquer significado intrínseco. Continuando com sua análise das relações entre trabalho e lazer, destaca, no item "a grande ruptura", que a moral da antiga classe média, com relação ao trabalho, foi substituída por uma ética do lazer. Essa substituição implicou, segundo o autor, uma "ruptura profunda e quase absoluta entre o trabalho e o lazer" (Ibid., p. 254). Essa ruptura e a maior importância atribuída às horas de folga influenciam os significados do trabalho e determinam os objetivos e aspirações populares. 
Outras contribuições importantes de Mills são suas reflexões sobre a alienação no trabalho, sobretudo dos "colarinhos brancos", a classe média ("ele entedia-se no trabalho, enerva-se no lazer, e é essa terrível alternância que o esgota”, [Idem, p. 18]), mas que atinge toda a sociedade. Especificamente quanto aos "colarinhos brancos", situados basicamente no setor terciário (serviços) da economia, destaca o que podemos chamar de dupla alienação, uma vez que eles "não vendem apenas seu tempo e energia, mas também suas personalidades. Vendem por semana ou por mês o sorriso e os gestos amáveis, e devem exercitar a pronta repressão do ressentimento e da agressividade" (Ibid., p. 19).

O autor destaca também o papel da mídia no entretenimento, no lazer e no consumo, destacando que o quadro da existência passa a ser fixado não pelas instituições tradicionais, vendo assim as comunicações de massa substituírem a tradição. Coloca que o trabalho é visto de maneira separada do resto da vida, como um “meio desagradável de atingir um fim posterior, situado em qualquer parte do domínio do lazer (Ibid., p. 254).

Conclui que: "cada dia os homens vendem pequenas parcelas de si mesmos para tentar comprá-las de novo cada noite e fim de semana com a moeda do "divertimento"" (Ibid., p. 255).

Embora reconhecendo que o campo do lazer "torna-se o centro das influências formadoras da personalidade e dos modelos com os quais o homem se identifica" (Ibid., p. 256), o autor adota uma perspectiva "funcionalista" do lazer, ainda que crítica, com nuança "romântica" (MARCELLINO, 2010).

O sociólogo francês Roger Caillois (1913-1978) foi um estudioso, entre outras questões, do lúdico manifestado no jogo, particularmente em Os jogos e os homens: a máscara e a vertigem (1990), publicado originalmente em 1958. 
Partindo do legado de Huizinga, o autor faz toda sua análise a partir da classificação dos jogos, "em quatro rubricas principais, conforme predomine, nos jogos considerados, o papel da competição, da sorte, do simulacro ou da vertigem" (CALlOIS, 1990, p. 32) (Agon, Alea, Mimicry e Illinx). Coloca os jogos num continuum que vai da "paidia" (improvisação e alegria geral) ao "ludus" (organização, regras, com “intenção civilizadora”) (p. 47-48).

Mais recentemente, nas quatro últimas décadas do século $\mathrm{XX}$, alguns autores se dedicaram ao assunto. Dentre eles destacam-se Kaplan, Godbey, De Grazia, Fourastié, Lefebvre, Rybczynski e Ariès.

Max Kaplan (1911-1998), em Leisure in America (1960), traz importantes contribuições para o conceito de lazer, entre elas a de que qualquer coisa ou atividade específica pode ser a base do lazer. Destaca entre seus elementos básicos: uma antítese ao "trabalho", a minimização dos compromissos sociais impostos, a abordagem psicológica de liberdade e um âmbito que vai da inconsequência e do descaso à seriedade e importância, tendo o "lúdico" como caracterização frequente.

G. Godbey (1975) contribui para a possível construção de uma teoria do lazer, entre outras discussões que abordam diversos questionamentos, com o conceito de "antilazer", ou seja, as atividades realizadas compulsivamente, como meio e não fim em si mesmas, baseadas na percepção de necessidade. São impostas de fora para dentro, e nelas se observam a ansiedade, muita preocupação com o tempo e autonomia pessoal mínima.

No Brasil, o conceito de "antilazer" é desenvolvido por Cavalcanti (1983) em sua crítica ao movimento "Esporte para todos".

Sebastian De Grazia (1917-2001) traz uma contribuição bastante importante aos estudos do lazer em sua obra Tiempo, trabajo y ocio (1966), na qual analisa o aspecto 
"tempo" e as relações trabalho e lazer. Sua mais importante contribuição diz respeito à compreensão do lazer, não apenas no contexto da sociedade americana, mas como esfera da vida humana sobre a qual uma reflexão aprofundada faz-se cada vez mais necessária quando se almeja pensar as sociedades em sua totalidade. De Grazia concebe o lazer de forma diferente de outros autores que tratam o tema, que o entendem como uma conquista da classe trabalhadora, pós-Revolução Industrial. De Grazia entende o lazer como aquele ideal de vida criado pelos gregos; para este autor, conforme mencionado anteriormente, o lazer é uma condição humana dificilmente observada na sociedade por ele analisada.

Apesar de tais divergências e indefinições, as informações trazidas à luz pelo trabalho deste autor têm grande valor para o pensamento do lazer, uma vez que propõem formas de pensá-lo enquanto objeto de estudos e pesquisas, enquanto esfera da vida influenciada pelos meios de comunicação de massa, como parte da lógica do consumo característica da sociedade capitalista e como possibilidade de desenvolvimento dos seres humanos.

Segundo De Grazia, para que o lazer volte a ter lugar privilegiado e para que possamos um dia falar em uma sociedade do lazer, será necessário que a humanidade se liberte do domínio das máquinas como fatores determinantes de como os indivíduos ocupam seu tempo e conduzem suas vidas.

Tendo em vista, porém, os avanços da tecnologia com que a sociedade moderna convive de modo crescente, aliados às influências da mídia sobre os modos de consumo, a libertação sugerida pelo autor torna-se bastante distante da possibilidade de concretização, ao menos na atualidade.

Jean Fourastié (1907-1990) manifesta sua grande esperança no progresso técnico e na produtividade e suas relações com o lazer. Ao se proceder à análise de 
algumas obras $^{3}$ do economista francês Jean Fourastié, percebe-se sua preocupação com a economia baseada no trabalho humano, mediada pela produção e consumo. Nota-se também a relação entre o progresso técnico, a produtividade e o lazer, destacando-se o turismo como uma das possibilidades abertas pelo progresso técnico, tema principal das teorias do autor.

Fourastié (1961, 1967 e 1971) analisa o progresso técnico e constata sua ação sobre os fatos econômicos e sociais relacionados com o nível de vida, o poder financeiro e o estilo de vida dos indivíduos, no que diz respeito às condições profissionais e à estrutura de produção e consumo.

Mais realista, e em condições históricas privilegiadas, Fourastié (1967) colocava que num futuro próximo, no século XXI, seis horas diárias de trabalho seriam suficientes para atender as populações, enquanto Lafargue, no final do século XIX (1970), pregava um número de três horas, e Russel, em 1932 (1977), advogava que seriam quatro horas.

O que se espera do futuro comporta pelo menos dois exercícios de abordagens: o de futurologia e o da esperança, manifestadas na Utopia. Fourastié opta pela segunda abordagem, enquanto outros autores, como De Masi (1999a, 1999b, 1999c, 2000, 2001a e 2001b), em sua vinculação trabalho/lazer, ou trabalho/ócio, colocam a instauração de uma civilização do ócio, já vislumbrada por Dumazedier sob o nome de "civilização do lazer” (DUMAZEDIER, 1973a, 1973b, 1977). Dumazedier é um de seus apologistas, inclusive em textos mais recentes, como "Eloge de la folie" (1990).

A futurologia poderia ser caracterizada como um recurso ideológico "funcionalista", de modo geral e também quando o assunto é o lazer.

3 A produtividade (1961), publicada pela primeira vez em 1949; As 40.000 horas: para onde caminha o trabalho da humanidade (1967), publicada pela primeira vez em 1965; e A grande esperança do século XX (1971), publicada pela primeira vez em 1945. 
Dessa forma, a esperança de Fourastié, o distingue dos autores futurologistas, que pregavam o advento das sociedades de lazer, ou de ócio, mantidos a estrutura e o modo de produção vigentes.

O sociólogo marxista francês Henry Lefebvre (1901-1991) contribui significativamente em suas obras para a compreensão do espaço, como produção social, e da cidade, uma de suas expressões (1974, 1980 e 1991).

Em A vida cotidiana no mundo moderno (1980), obra publicada em 1968, após examinar criticamente diferentes denominações para a sociedade atual, inclusive os conceitos de "sociedade de lazer" (1980, p. 60-62) e de "sociedade de consumo" (1980, p. 62-67), Lefebvre caracteriza-a como "sociedade burocrática de consumo dirigido", marcando, assim, o "caráter racional dessa sociedade, como também os limites dessa racionalidade (burocrática), o objeto que ela organiza (o consumo no lugar da produção) e o plano para o qual dirige seu esforço a fim de se sentar sobre: o cotidiano" (1980, p. $68)$.

Sua visão de lazer destaca a passagem da "festa" para o lazer "consumo", distinguindo duas espécies de lazeres "bem distintos, 'estruturalmente' opostos": a) o lazer integrado na cotidianidade (leitura de jornais, televisão etc.), que deixa uma insatisfação radical [...]: b) a espera da partida, a exigência de uma ruptura, a vontade de evasão: o mundo, as férias, o LSD, a natureza, a festa, a loucura (cf. 1980, p. 95).

Conclui pela necessidade de questionamento da cotidianidade inteira. Destaca, ainda, a necessidade de caminharmos rumo à "revolução cultural permanente", apontando níveis como o econômico, o político e o cultural. A esse último, liga a "nossa revolução cultural", destacando-a como um "conceito", tendo por base o marxismo. Enumera, também, alguns "aspectos ou elementos do processo revolucionário": reforma e revolução sexual, destacando as relações "feminino-masculino"; reforma e revolução 
urbanas, destacando o direito à cidade; a festa reencontrada, "amplificada, superando a oposição 'cotidianidade-festividade', realizando-se na e pela sociedade urbana [...]" (1980, p. 216).

Witold Rybczynski, arquiteto e pensador, contribui com suas análises do aspecto "tempo" e, mais particularmente, com a história do "fim de semana". Publicado em 2000, Esperando o fim de semana foi escrito entre março de 1989 e dezembro de 1990, segundo o próprio autor, inspirado em Veblen. É um estudo sobre o tempo, mostrando como a prática do descanso religioso dominical evoluiu para a instituição do fim de semana, hoje assumindo ares de nova tarefa, com uma intensa agenda de lazer. $\mathrm{O}$ autor define o trabalho como "mais um ensaio longo do que uma obra de pesquisa".

Philippe Ariès (1914-1984), historiador francês que fez parte do movimento "História Nova", tem a iconografia como base principal de seus trabalhos e contribuiu significativamente aos estudos de lazer, no conjunto de sua obra, com destaque especial para a História da vida privada, em cinco volumes, do qual foi um dos organizadores.

Sua História social da criança e da família (1976), publicada em 1973, defende duas teses: "A minha primeira tese é uma tentativa de interpretação das sociedades tradicionais. A segunda pretende mostrar o novo lugar assumido pela criança e a família em nossas sociedades industriais" (ARIÈS, 1976, p. 11). Dessa forma, traz uma série de conceitos fundamentais para quem se dedica aos estudos do lazer, entre os quais a constituição histórica do sentimento de infância ("moralização" e "paparicação"). Mas, é particularmente no capítulo em que dá sua "pequena contribuição à história dos jogos e brincadeiras", que Ariès faz sua incursão mais importante, a nosso ver, para quem se dedica aos estudos do lazer.

A partir da observação da "vida de uma criança no início do século XVII" (Ibid., p. 82), o autor examina as relações festa (lazer) e trabalho, concluindo que, ao se partir 
"de um estado social em que os mesmos jogos e brincadeiras eram comuns a todas as idades e a todas as classes" (Ibid., p. 124), chega-se ao fenômeno de "abandono desses jogos pelos adultos das classes sociais superiores, e, simultaneamente, sua sobrevivência entre o povo e as crianças dessas classes dominantes" (Ibid., p. 124). Chama a atenção para o fato de que "na Inglaterra os fidalgos não abandonaram, como na França, os velhos jogos, mas transformaram-nos, e foi sob formas modernas e irreconhecíveis que esses jogos foram adotados pela burguesia e pelo 'esporte' do século XIX" (Ibid., p. 124).

$\mathrm{O}$ autor ressalta também o fato de que "a antiga comunidade dos jogos se tenha rompido ao mesmo tempo entre as crianças e os adultos e entre o povo e a burguesia", advogando que "essa coincidência nos permite entrever [...] uma relação entre o sentimento de infância e o sentimento de classe" (Ibid., p. 124).

Deve-se destacar, também, a contribuição da chamada "sociologia do lazer". Nesse caso, as principais contribuições, em termos de repercussão no Brasil, são as de Parker e Dumazedier.

Parker, em sua obra A sociologia do lazer (1978), aborda o lazer de maneira direta, trazendo contribuições importantes sobre a epistemologia, a conceituação do lazer - aproximando "recreação" e "lúdico" -, seu contexto cultural, as relações entre ele e as outras esferas da vida e sobre o planejamento e as políticas de lazer.

Com relação às questões epistemológicas, embora reconhecendo as contribuições da chamada "sociologia do lazer", destaca seu caráter interdisciplinar e a contribuição possível das várias ciências sociais e das várias profissões que ele envolve (PARKER, 1978, p. 13-14). 
Posiciona-se contrário à ideia de uma "sociedade do lazer" já existente ou por nascer, contradizendo, assim, vários autores que fizeram exercícios de futurologia, como Joffre Dumazedier, advogando uma "sociedade com lazer" (Ibid., p. 184).

Joffre Dumazedier (1915-2002), sociólogo francês, foi sem dúvida, o autor que mais influenciou os estudos do lazer no Brasil, seja com seguidores ou com críticos, quer com seus conceitos, quer com suas "categorias" de análise.

Em termos de epistemologia, Dumazedier (1973a) coloca que a "sociologia do lazer" deve ser a responsável por seus estudos, e delimita o campo sociológico válido como sendo a "sociologia empírica" do lazer. Sua posição é claramente positivista. Na mesma obra, o autor coloca seu conceito de lazer, analisando o que chama de querela das definições, como atividades desenvolvidas no tempo livre, com determinadas características de atitude: caracteres liberatório, desinteressado, hedonístico e pessoal.

Em Lazer e cultura popular (1973a), o conceito de lazer é novamente retomado e explicitado como

um conjunto de ocupações às quais o indivíduo pode entregar-se de livre vontade, seja para repousar, seja para divertir-se, recrear-se e entreter-se, ou, ainda, para desenvolver sua informação ou formação desinteressada, sua participação social voluntária ou sua livre capacidade criadora após livrar-se ou desembaraçar-se das obrigações profissionais, familiares e sociais. (DUMAZEDIER, 1973a, p. 34).

Embora o conceito tenha merecido uma série de críticas, em virtude de seu caráter "funcionalista", que não considera, entre outros aspectos, a dinâmica histórica e restringe-se às "ocupações" ou atividades, deve-se ressaltar sua importância histórica por seu caráter abrangente, não segmentando o lazer neste ou naquele conteúdo, mas procurando entendê-lo a partir de uma perspectiva mais ampla. Seu conceito de "semilazer" é bastante criticado pelos analistas da "sociologia do lazer". 
Quanto à classificação das atividades, parte da relação estabelecida entre os interesses que os indivíduos procuram satisfazer e os conteúdos culturais que buscam para tal, e enquanto interesses predominantes, que se inter-relacionam: físico-esportivos, artísticos, manuais, intelectuais e sociais. Traz importantes contribuições quanto aos gêneros das atividades - prática, de assistência e informação - e quanto aos níveis de desenvolvimento das atividades pelos indivíduos - baixo, médio ou alto, primeiro "em fase dos valores uma cultura acadêmica, de vanguarda" (DUMAZEDIER, 1973a, p. $103)$.

Suas “categorias de análise" são retomadas no livro Planejamento do lazer no Brasil: a teoria sociológica da decisão (1980b), em que explica a matriz teórica que o orienta. Na retomada dos níveis de desenvolvimento das atividades pelos indivíduos, o autor os caracteriza em elementar ou conformista, médio ou crítico e superior ou inventivo (criativo). Visto criticamente, o livro traz importantes contribuições para políticas de ação na área.

Essas categorias também são retomadas em Questionamento teórico do lazer (s.d.), onde o autor traz importantes reflexões sobre a "axiologia do lazer", e em Lazer e cultura popular (1973b). Dumazedier considera a cultura popular como a mais divulgada ou consumida e vincula o lazer à educação. Os conteúdos culturais do lazer são retomados e analisados mais densamente em Valores e conteúdos culturais do lazer (1980a).

Outra importante "categoria de análise" diz respeito à animação cultural vinculada às políticas de ação. O autor distingue uma "estrutura" de animação, de forma piramidal, constituída por três partes: animadores voluntários, na base; animadores semiprofissionais, no meio; e animadores profissionais no topo (s.d.). 
Dumazedier também faz importante discussão sobre a atividade e passividade no lazer, e os valores positivos que se associam à primeira, e os valores negativos que se associam à segunda, argumentando que o mais importante são os níveis em que as atividades são desenvolvidas (conformista, crítico e criativo). A partir deste ponto de vista, uma atividade pode ser ativa ou passiva, independentemente do gênero (prática, assistência ao espetáculo ou busca da informação) em que é realizada.

Finalmente, distingue uma sociedade do lazer que estaria por vir, na continuidade da ordem vigente, manifestando uma visão de "futurologia", muito visada pelos críticos da chamada "sociologia do lazer" (DUMAZEDIER, 1973a, 1973b, 1977). Dumazedier é um de seus apologistas, inclusive em textos mais recentes, como "Eloge de la folie" (1990).

Vários autores criticam a "sociologia do lazer", em geral. No Brasil esta crítica é feita especialmente por Faleiros (1980) e Valle (1988).

Fundamentada em referências de Malinowski, Marx e Baudrillard, Faleiros faz uma crítica a Joffre Dumazedier, classificando sua abordagem como "funcionalista" e criticando seu conceito de lazer como um "invólucro vazio para ser preenchido com as atividades que são desenvolvidas em função de determinadas necessidades, desde que realizadas distintamente de certas obrigações institucionais" (1980, p. 61). Aduz que esse conceito de lazer não considera a historicidade e busca seu conteúdo "organizando o mundo da aparência" (1980, p. 61).

A autora considera uma unidade entre tempo de trabalho e tempo de não trabalho, vendo o lazer como um "momento necessário à reposição e reprodução da força de trabalho" (1980, p. 51).

Já para Valle, o estudo das questões relacionadas ao lazer "foi sempre profundamente caracterizado por uma busca direta de manipulação ideológica" (1988, 
p. 44), com a ausência de referenciais teóricos sólidos, sendo substituída por postulações gerais e imprecisas, relacionadas falaciosamente a "dados empíricos isolados e a 'previsões' nunca realizadas" (Ibid., p. 44). É dessa perspectiva que situa a "sociologia do lazer" tanto no exterior quanto no Brasil.

É nesse sentido que examina a questão da "lógica dominante, lógica de dominação", a partir das contribuições de Marx, concluindo por um duplo aspecto ao considerar o lazer "atividade instrumentalizada e instrumentalizável pelo trabalho, alienação e empobrecimento e, por outro lado, necessidade radical capaz de conduzir a um dado momento a classe trabalhadora a transcender os limites socialmente impostos à sua liberdade" (Ibid., p. 48).

É importante destacar a contribuição da autora para o entendimento do lazer como resistência na sociedade brasileira. E é dessa perspectiva que propõe a compreensão da realidade do lazer, que "parece emergir de uma dinâmica social onde lógicas opostas estão em ação, e onde a prática popular pode ser entendida como uma forma de resistência que assume múltiplos significados” (Ibid., p. 50).

Conclui pela proposição do lazer como objeto necessário de estudo.

Muitos outros autores têm contribuído com suas reflexões para os estudos do lazer, como os teóricos da chamada "Escola de Frankfurt", Norbert Elias e seus seguidores, Thompson e De Masi.

Ao analisarmos as obras dos pensadores da Escola de Frankfurt (WIGGERSHAUS, 2002), concluímos que eles contribuíram, dentro do contexto em que viveram e as produziram, para a constituição de uma possível teoria sobre o lazer. $\mathrm{O}$ ponto que os une, nas obras investigadas, é notadamente a difusão e criação da cultura e suas relações com a chamada "indústria cultural”. Os pontos divergentes dizem respeito à análise mais pessimista ou otimista sobre a contribuição da chamada "indústria 
cultural" para a emancipação humana, diante do quadro que se apresentava. Destacamse Benjamin, Adorno, Horkheimer, Fromm, Marcuse e Habermas.

Em Reflexões sobre a criança, o brinquedo e a educação (1984), Walter Benjamin (1892-1940) critica a forma como o adulto se intromete nos momentos de lazer infantil. Segundo o autor, acreditando que a brincadeira da criança tem seu conteúdo imaginário retirado do brinquedo, o adulto produz aquilo que imagina ser adequado. Para ele, ninguém melhor que a própria criança para produzir seus próprios brinquedos e elaborar suas brincadeiras, pois, ao contrário do que se pensa, é a imaginação infantil que determina o conteúdo da brincadeira e a utilização do brinquedo.

O segundo ponto importante de sua crítica diz respeito à tentativa de incluir o lúdico na literatura infantil e na educação. Benjamin critica o tratamento dado às crianças, de forma infantil, com o objetivo de aproximar-se delas. Considera isto patético, cômico (BENJAMIN, 1984). Porém, elogia a forma como o tratamento dos textos e imagens, feitos de forma clara e compreensível, fazem com que a criança se divirta e seja estimulada a aprender de forma agradável. Segundo o autor, é o lúdico que faz com que o hábito entre na vida do indivíduo.

Em A obra de arte na era de sua reprodutibilidade técnica (BENJAMIN, 1994), o autor aborda o que chama de "teses sobre as tendências evolutivas da arte, nas atuais condições produtivas", que seriam as inovações e possibilidades no campo da arte, esta no contexto em que reproduzida de forma técnica, com o aparecimento de novas formas de manifestações artísticas, por exemplo, a fotografia e o cinema.

Benjamin afirma que a reprodução técnica, que teria modificado a forma de produção e recepção da arte, bem como eliminado a "aura" que existia nas obras "tradicionais", tornou a arte menos distante e mais acessível. Na medida em que a arte 
não tem mais função de culto e encontra-se próxima e acessível às massas, adquire um valor revolucionário. A atitude revolucionária e crítica das massas dar-se-ia por meio da diversão e da distração.

A tese de Benjamin foi refutada por Adorno (1903-1969) e Horkheimer (18751973), como visto em “A indústria cultural: o esclarecimento como mistificação das massas", parte integrante da obra Dialética do esclarecimento (1985), na qual o termo "indústria cultural" denuncia o que antes seria arte e tornou-se técnica, sendo produzida em nível comercial e autoritário, como forma de adaptar a mercadoria às massas, bem como as massas às mercadorias. Seria dominação por meio da disseminação de produtos padronizados, destinados ao consumo das massas, como se tivessem que satisfazer necessidades iguais. Essa padronização aceita sem resistência culminaria na falta de autonomia dos indivíduos e em sua dominação inconsciente. Adorno e Horkheimer identificam a indústria cultural agindo nos momentos de lazer, reprimindo inconscientemente as liberdades individuais, padronizando e conformando as massas, condicionando-as ao mundo do trabalho.

Em Prismas: crítica cultural e sociedade (1998), Adorno fala de uma sociedade opressora, altamente competitiva - tendo em vista o mercado -, repressora das liberdades individuais. Os indivíduos seriam "indivíduos massificados" - mesmo que inconscientemente - e a cultura, uma mercantilizada como todas as esferas da vida humana, padronizada a toda a sociedade. Para Adorno, em sua sociedade contemporânea há um padrão estabelecido, ao qual dificilmente se oferece resistência, e mesmo os poucos que tentam resistir não podem esquivar-se totalmente das características da cultura e sociedade da qual fazem parte.

Segundo Adorno, o indivíduo estaria incluído numa sociedade em que seu senso crítico não teria importância, ou pior, estaria aprisionado. O entretenimento seria, então, 
uma forma de extensão da dominação, aqui de forma inconsciente, no tempo livre, nos momentos de lazer, atuando enquanto forma de desviar o pensamento e a atenção do indivíduo.

Já em Tempo livre (1995), Adorno destaca que a expressão "tempo livre" indicaria a existência de um "tempo não-livre". Essa divisão do tempo subjugaria, quase totalmente, o tempo livre ao tempo de trabalho.

O autor fala de funções sociais que definem as pessoas até mesmo em seu tempo livre. (ADORNO, 1995).

Negando a validade do tempo dividido em duas metades, um vinculado ao outro, Adorno defende que tempo livre deveria ser o tempo que o indivíduo tem por benefício, e não privilégio, para decidir, escolher e organizar segundo suas próprias vontades. Porém, segundo o autor, isso só seria possível em pessoas emancipadas, não naquelas subordinadas a uma realidade social na qual o tempo livre é uma sombra do trabalho.

Erich Fromm (1900-1980) foi psicanalista, cientista social e filósofo. Alemão de origem judaica, teve participação nas pesquisas do Instituto de Pesquisa Social - a chamada Escola de Frankfurt - entre o fim dos anos 1920 e início da década de 1930. Foi autor de uma vasta obra que abrange os campos das chamadas ciências humanas, sendo reconhecido humanista, fiel à tradição clássica do humanismo alemão, que acrescenta ao humanismo uma dimensão psicanalítica.

Psicanálise da sociedade contemporânea (FROMM, 1983) é considerada uma das principais obras de Erich Fromm, escrita e publicada na década de 1950. Como o próprio Fromm afirma, esse trabalho dá continuidade às obras anteriores, ambas da década de 1940, O medo à liberdade (1974) e Análise do homem (1976). 
Em $O$ medo à liberdade, publicado no início da década de 1940 e muito marcado pelo contexto da Segunda Guerra Mundial, Fromm elabora um estudo acerca do significado da liberdade para o homem moderno.

Esse estudo faz um diagnóstico do homem inserido na sociedade contemporânea. O principal foco de Fromm é a busca do significado da liberdade para o homem moderno e o porquê de ele procurar escapar-lhe. Segundo destaca, sua resposta para essa questão é que a partir do fim da Idade Média o homem conquistou maior liberdade, porém essa liberdade trouxe consigo a percepção de individualidade. O homem passa a se reconhecer como indivíduo e não apenas como parte integrante de algo, como seria até o período medieval. Esse reconhecimento de si como indivíduo acarretaria sentimentos de solidão e impotência diante da vida e do mundo ao redor. Segundo Fromm, isso acarretaria um anseio por fugir à liberdade conquistada, anseio esse que faria com que o homem buscasse segurança na submissão a um líder, raça ou Estado.

Já em Psicanálise da sociedade contemporânea, Fromm aborda a questão da liberdade destacando a vida na democracia do século XX como outra forma de fuga à liberdade.

Análise do homem, de meados da década de 1940, é um trabalho em que Fromm desenvolve "a ideia de várias orientações de caráter, substituindo o sistema freudiano do desenvolvimento da libido por outro da evolução do caráter em termos interpessoais" (FROMM, 1983, p. 11).

Afirmando ser um livro no qual tratará da questão "da ética, das normas e valores que levam à compreensão do Eu humano e de suas potencialidades" (1976, p. 9), Fromm faz uma análise de sua sociedade contemporânea como um período em que, devido à razão, o homem avançou muito na questão do domínio das forças físicas e 
edificou um material inacreditável. Mas destaca que, embora haja orgulho por essas realizações de suposta dominação da natureza e otimismo quanto à situação futura da humanidade, o homem sente-se inquieto e impotente em relação à sua vida social e à sociedade. Isso ocorreria porque, enquanto esteve ocupado criando maneiras de dominar a natureza, o homem perdeu de vista seu significado, esqueceu de si mesmo e converteu-se em escravo da máquina por ele mesmo construída, escravo de suas realizações de progresso.

A crítica de Fromm acerca das produções dos meios de comunicação e das formas como são utilizados é algo marcante em suas considerações sobre as questões relacionadas ao lazer. Sugere, por exemplo, que esses meios de comunicação deveriam proporcionar ilustração e aprimoramento da mente por meio de boas produções musicais, literárias, cinematográficas e radiofônicas financiadas pelo governo. Porém, a realidade que vê é muito diferente: os anúncios e as coisas ordinárias envenenam as mentes dos consumidores. Em outro trecho, por exemplo, Fromm critica a forma como a televisão, os quadrinhos e as notícias veiculadas em jornais influenciam a violência e a crueldade.

Para Fromm, o homem da sociedade ocidental do século XX não sabe o que fazer e como lidar com seu tempo livre do trabalho. O homem alienado é infeliz e está ansioso para matar o tempo, diz Fromm. Para isso, consome diversão como forma de distrair-se de sua infelicidade. O consumo da diversão dá-se pelos meios de comunicação e pelos produtos culturais comercializados. Sem esse "remédio" cinema, rádio, TV e esporte -, o homem seria deixado por conta de seus próprios recursos.

Outras considerações de Fromm acerca do tempo livre do trabalho, diretamente relacionadas com o que já foi dito, dizem respeito à relação do homem do século XX 
com as atitudes de consumo. Segundo o autor, os seres humanos têm sempre a necessidade de consumir algo novo, novidade que ama até que surja algo ainda mais novo. Fromm faz uma série de considerações sobre o tempo livre. Com base nelas, podemos concluir que o tempo livre do trabalho, para Fromm, não é algo verdadeiramente livre. Estaria acorrentado aos aparatos culturais, aos meios de comunicação, à necessidade de fuga da infelicidade humana, canalizada no consumo como um remédio contra suas ansiedades. Isso resultaria em pessoas conformadas, bem como influenciadas por aquilo que consomem pelos meios de comunicação.

Em A ideologia da sociedade industrial (1982), Herbert Marcuse (1898-1979) afirma que a sociedade industrial, pela forma como é organizada para se manter em desenvolvimento, destrói as necessidades individuais na medida em que as necessidades políticas da sociedade tornam-se as aspirações individuais. Isso acontece porque a lógica imposta é de que vale a pena suprimir o real desejo individual por aquilo que supostamente seria melhor para a sociedade como um todo. $\mathrm{O}$ fato de essa realidade ser aceita como razão faz com que toda liberdade seja suprimida e a própria noção de liberdade seja invertida.

Sob esta ótica, o lazer é parte integrante e inseparável das características da sociedade industrial. Assim, segundo Marcuse, as atividades praticadas como lazer, sejam elas em grupo ou individuais, estão regidas pela sociedade, dominadas por seus interesses, manipuladas como meio de manutenção da dominação estabelecida.

Em Eros e civilização (1968) o autor faz um diagnóstico da chamada sociedade moderna, semelhante ao abordado em A ideologia da sociedade industrial: o homem unidimensional (1982).

Para Marcuse, o lazer, inserido no contexto da sociedade moderna, é o curto tempo livre dos indivíduos, no qual teriam direito ao prazer. Porém, esse tempo livre é 
apenas uma parte menor na divisão do tempo diário, e ainda sofre com formas conscientes e inconscientes de controle nas quais o indivíduo é levado a desejar aquilo que se crê que deve desejar, e acreditar que são desejos autônomos. $\mathrm{O}$ autor afirma de forma direta que a indústria do entretenimento controla diretamente o tempo de lazer.

Destacando a produtividade, ligada ao princípio de desempenho “como um dos mais protegidos valores da cultura moderna", Marcuse contrapõe-lhe a ideia do jogo: o jogo é improdutivo, é inútil precisamente porque anula as características repressivas e exploradoras do trabalho e do lazer. Em A ideologia da sociedade industrial (1982), obra centrada na análise das tendências das sociedades contemporâneas mais altamente desenvolvidas, o mesmo autor distingue o lazer do tempo livre, cuja restrição é por ele considerada um dos fatores da ausência de liberdade no estado de bem-estar social, argumentando que as horas de lazer vicejam na sociedade industrial desenvolvida, mas não são livres por serem administradas pelos negócios e pela política (MARCUSE, 1982).

Jürgen Habermas é um filósofo e sociólogo alemão, membro do Instituto para Pesquisa Social de Frankfurt, a chamada Escola de Frankfurt, desde a década de 1950. Foi considerado por muitos seu principal herdeiro e representante, após a morte de Adorno, Horkheimer e Marcuse. Habermas representaria o que vários estudiosos consideram ser a segunda fase da Escola de Frankfurt, vistas as diferenças existentes entre seu pensamento e o dos clássicos representantes frankfurtianos, sobretudo em seus últimos trabalhos - o que, inclusive, faz com que muitos pesquisadores não considerem seu pensamento atual como herdeiro da Escola de Frankfurt (WIGGERSHAUS, 2002).

Pretendendo analisar as possíveis contribuições teóricas de Habermas para os estudos do lazer, as obras que mais se destacam são: Mudança estrutural da esfera pública - Investigações quanto a uma categoria da sociedade burguesa (1984), texto originado de 
sua tese de livre docência em 1961 e publicado como livro em 1962 (WIGGERSHAUS, 2002), bem como a Teoría de la acción comunicativa, I e II, de 1986 (HABERMAS, 1987a e 1987b).

Em linhas gerais, pode-se afirmar que Mudança estrutural da esfera pública, sob várias referências disciplinares, trata do que Habermas considera as condições históricas e sociais que levaram ao surgimento de uma esfera pública burguesa, analisando posteriormente as mudanças estruturais ocorridas nessa esfera pública em determinado período. Mudança estrutural na esfera pública é, segundo Wiggershaus, um "estudo sobre as mudanças de estrutura e função da opinião pública burguesa" (WIGGERSHAUS, 2002, p. 590). Essas mudanças, segundo Habermas, modificaram o comportamento das pessoas em relação ao lazer, e é esse aspecto do trabalho que será destacado.

Já Teoría de la acción comunicativa traz reflexões que servem de referencial teórico a pesquisadores que estudam questões relacionadas ao lazer numa perspectiva que não está estritamente ligada ao mundo do trabalho.

O sociólogo alemão Norbert Elias (1897-1990), dono de vasta obra, traz suas principais contribuições para uma possível teoria do lazer nos dois volumes de $O$ processo civilizador (1994), publicados originalmente em 1939 (na Suíça), e posteriormente, com sua redescoberta e valorização, em 1969 (alemão) e 1978 (inglês), e também no livro que divide com Eric Dunning, A busca da excitação (ELIAS; DUNNING, 1992).

Partindo de uma abordagem histórica, com base nos conceitos de civilização e cultura, Elias trata do desenvolvimento do processo civilizador e traz contribuições significativas para os estudos do lazer, principalmente no que tange às rupturas com a dicotomia (trabalho-lazer), que alimentavam os estudos em sociologia. Para Elias, trabalho e lazer devem ser compreendidos na forma de suas interdependências. 
O autor demonstra a importância dos estudos do lazer para a moderna sociedade urbano-industrial, destacando que eles se concentram em áreas-limite, como os meios de comunicação social (teatro, desportos etc.), ao passo que outros grandes campos das atividades de lazer raramente são tratados como temas centrais de investigação. Constata a falta de uma teoria central do lazer, ou seja, um quadro comum de investigação que aborde o tema em sua totalidade.

Outra questão importante é que Elias e Dunning não compreendem as tensões como algo do qual as pessoas fogem em suas práticas de lazer. Pelo contrário, entendem o lazer como uma busca por excitação e prazer que, por conta do controle exercido sobre os impulsos das pessoas, não podem ser manifestados na vida cotidiana. Nisso, um tipo de tensão agradável tem papel importante como quebra da rotina por meio de um perigo imaginário e provisório.

Edward Palmer Thompson (1924-1993), historiador britânico de inspiração marxista, contribuiu para a demonstração de que a classe trabalhadora não tem suas bases apenas na economia, valorizando assim a construção histórica de sua experiência. Para ele, "classe" é uma formação social e cultural. Thompson contribuiu, ainda, com os estudos culturais, desenvolvendo o que se pode chamar de marxismo culturalista.

Entre suas obras destacam-se, para a finalidade do nosso artigo: A formação da classe operária inglesa (1987), As peculiaridades dos ingleses e outros artigos (2002) e A miséria da teoria ou um planetário de erros: uma crítica ao pensamento de Althusser (1981), publicado originalmente em 1978.

Em "Tempo, disciplina de trabalho e o capitalismo industrial" (THOMPSON, 1998), Thompson elaborou um texto resultado de pesquisa na qual analisou novos costumes e valores formados a partir da marcação do tempo por meio do uso do relógio - abordando principalmente os séculos XVII, XVIII e XIX. Essa nova forma de marcar 
o tempo teria formado novos hábitos e nova disciplina de trabalho, impondo o surgimento de uma nova disciplina do tempo de trabalho que garantiria o controle do ócio, questões que seriam importantes na garantia do progresso do capitalismo industrial. Thompson ressalta que a imposição de uma nova disciplina, que contraria antigos hábitos populares de trabalho, resultou em contestação e luta pelo tempo redução de horas de trabalho.

O sociólogo do trabalho italiano Domenico De Masi apresenta muitos pontos de sombreamento com as questões do lazer e seus possíveis desdobramentos em termos de políticas institucionais, já a partir de um dos conceitos-chave no trabalho do autor: o "ócio criativo".

O trabalho de De Masi teve grande penetração no Brasil, principalmente pela mídia, seja em programas de entrevistas em televisão, revistas semanais e mesmo jornais, a partir do V Congresso Mundial do Lazer e do X Encontro Nacional de Recreação e Lazer (Enarel), promovidos pelo Serviço Social do Comércio (SESC-SP).

Para o âmbito de nosso trabalho, talvez a principal contribuição de De Masi seja "desencantar" o conceito de trabalho e "valorizar" o conceito de ócio, e assim, de modo indireto, o de lazer. A grande questão é como isso é feito. Nesse aspecto, De Masi situa-se na contramão dos autores da Sociologia do Trabalho, que normalmente, sem conceituar o lazer, contrapõem, em sua análise, o lazer concreto, alienado, ao trabalho ideal, em contrapartida aos autores da Sociologia do Lazer, que em sua maioria, contrapõem o lazer ideal ao trabalho concreto, alienado. Somos partidários da comparação entre categorias concretas entre si e categorias do devir entre si. Só assim as comparações podem ser estabelecidas de fato.

As propostas de De Masi com relação à educação para o lazer, ou educação para o ócio criativo, são interessantes, mas de forte cunho "idealista", pois nelas a educação e 
a escola apresentam-se desvinculadas da realidade social como um todo, e da construção de um projeto de sociedade, em que lazer e ócio desempenhem outro papel dentro de uma nova ordem social, socialmente distribuídos com justiça.

Percebe-se, assim, uma abordagem indireta do lazer em suas relações com o trabalho, no cotidiano da sociedade chamada por De Masi de pós-industrial, abordagem essa marcada por valores "funcionalistas", com nuanças "utilitarista" e "compensatória" (MARCELLINO, 2010), O entendimento do lazer dá-se, portanto, em sua “especificidade abstrata” (MARCELLINO, 1992), com base na concepção idealista de sociedade e na crença ingênua no progresso tecnológico. Isso contribui para reforçar ainda mais uma ação que colabora para a manutenção do status quo, uma vez que, entre outros aspectos, não leva em conta o contexto mais amplo e, assim, deixa de considerar o "todo inibidor" para o lazer - o conjunto de barreiras inter e intraclasses que, tendo como pano de fundo a questão socioeconômica, provoca as desigualdades quantitativas e qualitativas em sua apropriação.

Pelo menos cinquenta anos separam o desenvolvimento dos estudos sobre o lazer, em termos de abordagens diretas, na Europa e no Brasil. Lá, o contexto histórico que propiciou o interesse maior por essa questão, como vimos, está diretamente relacionado ao processo de industrialização. Aqui, muito embora também possa ser verificada a mesma relação, o assunto encontra-se mais vinculado à urbanização da vida nas grandes cidades.

A questão do lazer é motivo de preocupação relativamente recente entre os pensadores e pesquisadores brasileiros; bem mais nova, por exemplo, do que a fama de país do “carnaval e futebol". Até bem pouco tempo atrás, a maioria das abordagens sobre o tema ocorria de forma indireta, sobretudo quando se enfocava a questão do trabalho. Era o império da "moral cristã do trabalho", em plena "terra de Macunaíma". 
Ainda assim, nomes como Alceu Amoroso Lima (1947) e Vicente Ferreira da Silva (1964) ocuparam-se da questão do ócio, do significado do não-trabalho ou das perspectivas abertas pela automação.

Pelos autores que se dedicam à abordagem direta da questão, de início, no Brasil, notam-se escritos mais relacionados à recreação e não ao lazer como um todo. Nesse particular destaca-se Inezil Penna Marinho (1957).

Lazer operário: um estudo de organização social das cidades é considerado o primeiro livro brasileiro a tratar, de forma específica, da problemática do lazer. $\mathrm{O}$ trabalho, desenvolvido por José Acácio Ferreira, foi publicado em Salvador, em 1959, e caracteriza-se como um estudo empírico sobre trabalhadores assalariados naquele município - mais um indício de que é somente com a aceleração do processo de urbanização que o assunto ganha ressonância social em nosso país.

A obra é dividida em três partes principais: "Importância e significado do lazer"; "Lazer, industrialização e subdesenvolvimento" e "Lazer operário", destacando a importância da participação mais ativa dos empregados nas atividades de lazer.

O primeiro grande encontro para o estudo do lazer foi realizado em São Paulo, em outubro de 1969. O censo do ano seguinte mostrou, pela primeira vez, a supremacia numérica da população urbana brasileira. Aliás, os “clássicos” sobre o tema passam a ser traduzidos e publicados somente no final da década de 1960, com grande atraso em relação às edições originais. Na sequência, várias organizações desenvolvem trabalhos na área, ainda que possam ser questionados do ponto de vista institucional, mas que também contribuem com estudos. É o caso do Serviço Social da Indústria (SESI), nacional, e principalmente do Serviço Social do Comércio (SESC), de modo especial em sua regional de São Paulo. Os principais autores dessa fase são Renato Requixa (em 
São Paulo), Ethel Bauzer Medeiros (Rio de Janeiro) e Lenea Gaelzer (Rio Grande do Sul).

Renato Requixa, sociólogo, contribuiu com suas obras O lazer no Brasil (1977), em que faz uma abordagem do desenvolvimento histórico dos estudos do lazer no País, e Sugestões de diretrizes para uma política nacional de lazer (1980), na qual analisa os elementos que deveriam compor a política nacional de lazer.

Ethel Bauzer Medeiros contribuiu para a análise da relação entre lazer e planejamento urbano, publicando, entre outros estudos, O lazer no planejamento urbano (1971).

Lenea Gaelzer contribuiu com a publicação, entre outros, de Lazer: bênção ou maldição? (1979), e Ensaio à liberdade: uma introdução ao estudo da educação para o tempo livre (1985).

O três autores apresentam uma abordagem "funcionalista do lazer" (MARCELLINO, 2010), em várias nuanças, e também destacam, de modo significativo, as relações entre lazer e educação.

Significativamente, a universidade brasileira iniciou suas investigações sobre o assunto somente a partir da década de 1970. No decorrer das décadas seguintes cresceu muito o número de dissertações e teses defendidas nesse campo, principalmente relacionadas à educação e à produção cultural (turismo, educação física, artes etc.). Obedecendo a uma característica que se observa também em outras esferas do conhecimento, os estudos do lazer vêm se especializando, quer em termos de faixas etárias, de conteúdos de atividades, de relações com outras esferas de atividades (trabalho, educação, religião, família etc.), ou campos de intervenção (políticas públicas e privadas). 
A compreensão mais ampla das questões relativas ao lazer e seu significado para o ser humano contemporâneo, pelas próprias características abrangentes desse objeto de estudo, não pode ficar na dependência de uma disciplina exclusiva, exigindo as contribuições das várias Ciências Sociais, da Filosofia, e de profissionais ligados direta ou indiretamente ao campo de atividades.

Tendo em vista a natureza e o atual estágio dos estudos e a urgência do encaminhamento de propostas, é necessário, ainda, o desenvolvimento e a sistematização de experiências multidisciplinares nos estudos do lazer, buscando trabalhos interdisciplinares.

Atualmente, tem crescido o interesse pela área. O número de grupos de pesquisa registrados na base Lattes do $\mathrm{CNPq}$, com a palavra "lazer", cresceu de 41, no penúltimo levantamento (2002) para 84, no último (2004), e 184 (atual base corrente) das mais variadas áreas de conhecimento.

São vários os grupos de discussão e GTTs (Grupos de Trabalhos Temáticos) sobre estudos do Lazer existentes em sociedades científicas do País hoje. O tema vem ganhando espaço também em congressos e seminários de diversas áreas, como Educação Física, Turismo, Políticas Públicas, Antropologia etc., e seu Encontro Anual, o Enarel, já está em sua 21ª edição, em 2010.

\section{Considerações finais}

Retomamos aqui, as colocações efetuadas na Introdução deste artigo.

Destacamos e analisamos a contribuição dos autores clássicos pós-revolução industrial para a formulação de uma possível teoria do lazer. Eles têm as mais variadas formações, o que confirma que o lazer é um campo multidisciplinar de estudos, em busca da interdisciplinaridade. As contribuições dos autores devem ser levadas em conta 
segundo o tempo/espaço em que viveram e suas filiações ideológicas. Suas abordagens ora são diretas, ora são indiretas (MARCELLINO, 2010, 1992), e a consideração do lazer ocorre tanto numa perspectiva idealista quanto concreta (MARCELLINO, 1992). No conjunto, os autores demonstram que o lazer tem sua especificidade (MARCELLINO, 1992), mas que deve ser entendido no plano cultural do qual faz parte e em suas relações com o terreno das obrigações, destacando-se as relações lazer e trabalho

Dessa forma, procuramos contribuir: 1.para o embasamento teórico de estudos que problematizem o lazer enquanto manifestação cultural e suas relações com as esferas da vida social, como o trabalho, a educação, a saúde, a religião etc.; 2 . para o embasamento teórico dos processos de formação de pessoal para atuação na área; e 3.para o embasamento teórico na formulação de políticas de atuação na área.

Vimos que o lazer ora é conceituado considerando-se os "aspectos tempo/espaço", e ora os "aspectos de atitude", mas que a tendência é levarem-se em conta esses dois aspectos.

Com relação aos estudiosos dos conteúdos culturais do lazer, o ponto que os une, nas obras investigadas, é notadamente a difusão e criação da cultura e suas relações com a chamada "indústria cultural". Os pontos divergentes dizem respeito à análise mais pessimista ou otimista no que diz respeito à contribuição da chamada "indústria cultural" para a emancipação humana, diante do quadro que se apresentava para cada um deles.

Quanto à sustentação ao método enquanto relação teoria e prática, ou processo discursivo, verificamos que os autores ora adotam abordagens "funcionalistas", ora “críticas", baseadas no "materialismo-histórico dialético" (MARCELLINO, 2010), e que essas últimas podem ser apenas "críticas", ou "crítico-criativas". 


\section{REFERÊNCIAS}

ADORNO, T. W. Palavras e sinais. Petrópolis: Vozes, 1995.

Prismas: crítica cultural e sociedade. São Paulo: Ática, 1998.

; HORKHEIMER, M. Dialética do esclarecimento: fragmentos filosóficos. Rio de Janeiro: Jorge Zahar, 1985.

ARIÉS, P. História social da criança e da família. 2. ed. Rio de Janeiro: Zahar, 1976.

BENJAMIN, Walter. Reflexões: a criança, o brinquedo e a educação. São Paulo: Summus, 1984.

Obras escolhidas. 7. ed. São Paulo: Brasiliense, 1994. v. 1.

CAILlOIS, R. O homem e o sagrado. Lisboa: Edições 70, 1988. (Coleção Perspectivas do Homem).

Os jogos e os homens: a máscara e a vertigem. Lisboa: Cotovia, 1990.

CAVALCANTI, K. B. Esporte para todos: um discurso ideológico. Boletim de Intercâmbio, Rio de Janeiro, Sesc, v. 4, n. 13, p. 12-19, jan.-mar. 1983.

CHAUI, M. Prefácio. In: LAFARGUE, P. O direito à preguiça. São Paulo: Hucitec, 1999.

DE GRAZIA, S. Tiempo, trabajo y ócio. Madrid: Tecnos, 1966.

DE MASI, Domenico. A emoção e a regra. Rio/Brasília: J. Olympio/UNB, 1999a.

A sociedade pós-industrial. São Paulo: Senac, 1999b.

Desenvolvimento sem trabalho. São Paulo: Esfera, 1999c.

O ócio criativo. 3. ed. Rio de Janeiro: Sextante, 2000.

A economia do ócio. 2. ed. Rio, Sextante, 2001a.

$2001 b$.

O futuro do trabalho. 6. ed. Rio de Janeiro/Brasília: José Olympio/UNB,

DUMAZEDIER, Joffre. Sociologia empírica do lazer. São Paulo: Perspectiva, 1973a.

Lazer e cultura popular. São Paulo: Perspectiva, 1973b.

A revolução cultural do lazer nos centros urbanos. Cadernos de lazer, São

Paulo, Sesc/Brasiliense, v. 1, p. 43-52, 1977. 1990.

New "eloge de la folie". World Leisure \& Recreation, v. 32, n. 4, p. 6-10,

Questionamento teórico do lazer. Porto Alegre: CELAR, s.d.

Valores e conteúdos culturais do lazer. São Paulo: Sesc, 1980a.

Sesc, $1980 \mathrm{~b}$.

Planejamento do lazer no Brasil: a teoria sociológica da decisão. São Paulo:

ECO, U. Como se faz uma tese. São Paulo: Perspectiva, 1977.

. Huizinga e o jogo. In:

Janeiro: Nova Fronteira, 1989. p. 269-285.

ELIAS, N. O processo civilizador. Rio de Janeiro: Jorge Zahar, 1994. 2 v. 
;; DUNNING, E. A busca da excitação. Lisboa: DIFEL, 1992.

FALEIROS, M. I. Repensando o lazer. Perspectivas, São Paulo, v. 3, 1980.

FERREIRA, J. A. Lazer operário: um estudo de organização social das cidades. Salvador: Livraria Progresso, 1959.

FORACCHI, M. A.; MARTINS, J. S. (Org.). Sociologia e sociedade. Rio de Janeiro: Livros Técnicos e Científicos, 1981.

FOURASTIÉ, Jean. A produtividade. 2. ed. São Paulo: Difusão Europeia do livro, 1961.

As 40.000 horas: para onde caminha o trabalho da humanidade. Rio de Janeiro: Forense, 1967.

A grande esperança do século XX. São Paulo: Perspectiva, 1971.

FRIEDMANN, G. O trabalho em migalhas: especialização e lazeres. São Paulo: Perspectiva, 1972.

FROMM, E. O medo à liberdade. Rio de Janeiro: Zahar, 1974. 1983.

Psicanálise da sociedade contemporânea. Rio de Janeiro: Guanabara Koogan,

Análise do homem. Rio de Janeiro: Guanabara, 1976.

GAELZER, L. Lazer: bênção ou maldição? Porto Alegre: Sulina/URGS, 1979.

Ensaio à liberdade: uma introdução ao estudo da educação para o tempo livre. Porto Alegre: D. C. Luzzato, 1985.

GRAMSCI, A. Literatura e vida nacional. Rio de Janeiro: Civilização Brasileira, 1978. Brasileira, 1979.

Os intelectuais e a organização da cultura. Rio de Janeiro: Civilização

Maquiavel, a política e o estado moderno. Rio de Janeiro: Civilização Brasileira, 1980.

Concepção dialética da história. Rio de Janeiro: Civilização Brasileira, 1981.

GODBEY G. Anti-leisure and Public Recreation Policy. In: PARKER et al. (Ed.). Sport and leisure in contemporary society. London: Polytechnic of Central London, 1975.

HABERMAS, J. Mudança estrutural da esfera pública: investigações quanto a uma categoria da sociedade burguesa. Rio de Janeiro: Tempo Brasileiro, 1984.

- Teoría de la acción comunicativa, I. Racionalidad de la acción y racionalización social. Madrid: Taurus, 1987a.

Teoría de la acción comunicativa, II. Crítica de la razón funcionalista. Madrid, Taurus, 1987b.

HUHNE, L. M. Metodologia científica: caderno de textos e técnicas. Rio de Janeiro: Agir, 2002.

HUIZINGA, J. Homo ludens. São Paulo: Perspectiva/USP, 1971.

KAPLAN, M. Leisure in America. New York: Wiley, 1960. 
LAFARGUE, P. O direito à preguiça. Lisboa: Estampa, 1970.

O direito à preguiça. São Paulo: Hucitec, 1999.

LEFEBVRE, Henri. La production de l'espace. Paris: Anthropos, 1974.

A vida cotidiana no mundo moderno. São Paulo: Ática,1980.

O direito à cidade. São Paulo: Moraes, 1991.

LIMA, A. de A. O problema do trabalho: ensaio de filosofia econômica. Rio de Janeiro: Agir, 1947.

MARCELLINO, N. C. Lazer e educação. 15. ed. Campinas: Papirus, 2010.

A dicotomia teoria/prática na Educação Física. Motrivivência. Santa Catarina, UFSC, ano VII, n. 8, p. 73-78, 1995.

O lazer: sua especificidade e seu caráter interdisciplinar. Revista Brasileira de Ciências do Esporte, CBCE, v. 12, p. 313-317, 1992.

MARCUSE, H. Eros e civilização. Rio de Janeiro: Zahar, 1968.

A ideologia da sociedade industrial. 6. ed. Rio de Janeiro: Zahar, 1982.

MARINHO, I. P. Educação física, recreação e jogos. Rio de Janeiro: Cia. Brasil, 1957.

MARX, K. O capital. São Paulo: Nova cultural, 1988. v. 1.

Manuscritos econômico-filosóficos. Lisboa: Edições 70, 1989.

MEDEIROS, E. B. O lazer no planejamento urbano. Rio de Janeiro: FGV, 1971.

MILLS, W. A nova classe média: white collar. Rio de Janeiro: Zahar, 1969.

PARKER, S. A sociologia do lazer. Rio de Janeiro: Zahar, 1978.

PARRA, F. D.; SANTOS, J. A. Metodologia científica. 5. ed. São Paulo: Futura, 2002.

PEREIRA, O. O que é teoria. São Paulo: Brasiliense, 1982.

RAMPAZZO, L. Metodologia científica. São Paulo: Loyola, 2002.

REQUIXA, R. O lazer no Brasil. São Paulo: Brasiliense, 1977.

Sugestões de diretrizes gerais para uma política nacional de lazer. São Paulo: Sesc, 1980.

RIESMAN, D. A multidão solitária. São Paulo: Perspectiva, 1975.

RUSSEL, B. Elogio do Lazer. Rio de Janeiro: Zahar, 1977.

RYBCZYNSKI, W. Esperando o fim de semana. Rio de Janeiro: Record, 2000.

SANTOS, A. R. dos. Metodologia científica: a construção do conhecimento. 2. ed. Rio de Janeiro: DP\&A, 1999.

SAVIANI, D. Educação do senso comum à consciência filosófica. São Paulo: Cortez/Autores Associados, 1980.

SEVERINO, A. J. Metodologia do trabalho científico. São Paulo: Cortez, 1980.

SILVA, V. F. da. Ócio e trabalho. In: Obras completas. São Paulo: Instituto Brasileiro de Filosofia, 1964. p. 283-296. v.1. 
THOMPSON, E. P. A miséria da teoria ou um planetário de erros: uma crítica ao pensamento de Althusser. Rio de Janeiro: Zahar, 1981.

Costumes em comum. São Paulo: Companhia das Letras, 1998.

As peculiaridades dos ingleses e outros artigos. Campinas: Unicamp, 2002.

A formação da classe operária inglesa. Rio de Janeiro: Paz \& Terra, 1987.

VALLE, L. A. B. do. O lazer como resistência. Fórum Educacional, Rio de Janeiro, v. 12, n. 4, 1988.

VEBLEN, T. A teoria da classe ociosa. São Paulo: Pioneira, 1965.

WIGGERSHAUS, R. Escola de Frankfurt: história, desenvolvimento teórico, significação política. Rio de Janeiro: Difel, 2002.

\section{Endereço do Autor:}

Nelson Carvalho Marcellino

Rua 14 de dezembro, 428 - apto. 41

13015-130 Campinas - SP

Endereço Eletrônico: Marcelin@supernet.com.br 